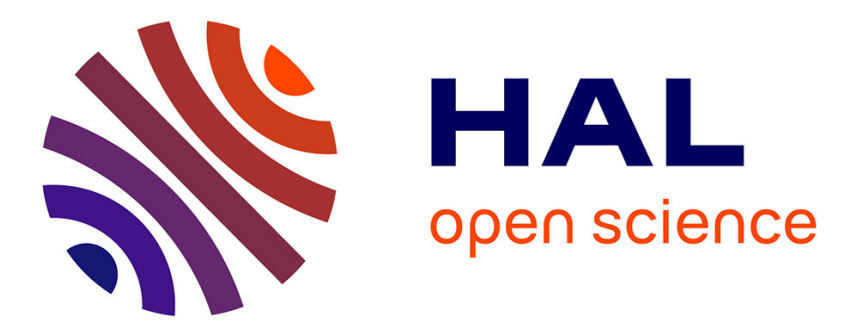

\title{
A Study on Developing a Decision Support Agent for Project Management
}

Shinji Mochida

\section{To cite this version:}

Shinji Mochida. A Study on Developing a Decision Support Agent for Project Management. 11th IFIP International Conference on Product Lifecycle Management (PLM), Jul 2014, Yokohama, Japan. pp.407-416, 10.1007/978-3-662-45937-9_40 . hal-01386545

\section{HAL Id: hal-01386545 \\ https://inria.hal.science/hal-01386545}

Submitted on 24 Oct 2016

HAL is a multi-disciplinary open access archive for the deposit and dissemination of scientific research documents, whether they are published or not. The documents may come from teaching and research institutions in France or abroad, or from public or private research centers.
L'archive ouverte pluridisciplinaire HAL, est destinée au dépôt et à la diffusion de documents scientifiques de niveau recherche, publiés ou non, émanant des établissements d'enseignement et de recherche français ou étrangers, des laboratoires publics ou privés. 


\title{
A study on developing a decision support agent for project management
}

\author{
Shinji Mochida ${ }^{1}$ \\ ${ }^{1}$ University of Marketing and Distribution Science, Japan
}

1shinji_mochida@red.umds.ac.jp

\begin{abstract}
The term "business system" refers to the methods which use to manage their information or knowledge. All companies employ business systems during the development of new software, mechanical equipment or other projects. There are several stages in development projects. There are stages of planning, development, system examination, and upgrade. However, because business knowledge and system development knowledge are united in the systems engineer individual, and the final system image is designed in the engineer' $s$ mind, the knowledge earned in the project is not adapted to the next system development project. Business knowledge and system development knowledge are different. A unification of measures for value of these two types of information is needed to treat the information equally. Then, this paper aims to achieve the decision support agent. This decision support agent should have the function of evaluating the value of knowledge and supporting judgment through all stages of the project. Additionally, because the environment around the system development is always changing, a function to evaluate the importance of knowledge from the data stream is needed so that the decision support agent may acquire and interpreted information in real time.
\end{abstract}

Keywords: project management, knowledge, agent, prioritization

\section{Introduction}

In business development projects, there are stages of planning, development, system examination, and upgrade. However, the person in charge of each these stages are different, and knowledge is not adapted to the next system development project. The uncertainty of scope, project duration and cost planning are repeated every time during development project due to knowledge shortages. These uncertainty causes schedule delays and cost overruns for the project [1][2]. One reason for cost overruns is that during the requirement assessment stages of a project, each project engineers' level of skill and experience is variable. This paper will use the term' subject ' to engineering staffs, engineers. Subjects may misunderstand the scope or requirements of the clients. Thus subjects do not know the best way to make the system at the early stage.The progress management is important and difficult work while the project is executed[3][4][5]. Generally in a business system development project, the feasible scope and the achievement method are designed after the subject investigates or 
studies the business for systematization. Business knowledge and system development knowledge are united in the systems engineer individual, and the final system image is designed in individual subject's mind. Thus, if business knowledge and system development knowledge are treated in the same way and used at the early stage of the project, it becomes possible to plan the duration and cost of the project accurately. Sub-optimization is necessary to develop the productivity and reduce costs of projects. Developing the productivity is important to achieve the sub-optimization. Offering appropriate knowledge to the all subject at appropriate time is necessary to develop the productivity and reduce costs of developing business systems.

\section{Previous Studies}

The current research studies techniques for the accumulation of information that is distributed and exists in the computer system, and also implements knowledge mining using a high performance computer [6]. However, there is no research on unification of values to deal with different information, such as business knowledge and the system knowledge, etc. in the same way. Moreover, there is no research that analyzes, evaluates the data stream including environmental information from consecutive work, and acquires knowledge continuously during a project [7]. Many researchers are studying techniques for implementing knowledge mining from information that has already been acquired, not real time processing [8].

\section{Productivity and Knowledge}

This paper aims to achieve a software agent that collects effective business knowledge and system development knowledge in the business system development projects. Figure 1 shows software agent. First this research need to create the function of compiling knowledge in Figure 1 for the software agent [9][10]. This software agent should have a function to evaluate the value of information automatically and support subject's judgment in all stages of the project. These judgments will allow subject to decide which work to do at what time. This paper will refer to this software agent as "the decision support agent". This decision support agent should is expected to accumulate, and maintain the knowledge acquired from all stages of the project, as well as to offer the knowledge to the all subject when necessary. When subjects engage in the project, it is thought that productivity increases as time spent on the project passes. This also assumes that productivity is low at the beginning of the work because necessary skills have not yet been developed and there is luck of detailed information necessary to start the work. We collected the productivity data from the computer system development project, and apply to the Weibull distribution. Thus we defined the model which is suitable for productivity curve in order to estimate productivity at specified time. The physical model and parameters are shown in Expression (1).If the productivity data collected from a computer system development project is substituted into Expression (1), then productivity at a certain time is obtained by $f(t)$ as shown in Figure 2 at time:t, and Table 1 shows the parameters 
obtained from the screen design work in a past system development project. Figure 2 was created using the parameters obtained the system development project.

$$
\begin{array}{r}
f(t)=K\left(1-\exp \left(-\left(\frac{t+a}{\eta}\right)^{m}\right)\right)+d \\
K: \text { final productivity } \\
a: \text { preparationdays } \\
\eta: \text { studyresistance } \\
m: \text { proficiency } \\
d: \text { workrepetition }
\end{array}
$$

Table 1. parameters gotten from the screen design work

\begin{tabular}{|c|c|c|c|c|}
\hline $\mathrm{K}$ & $\mathrm{a}$ & $\eta$ & $\mathrm{m}$ & $\mathrm{d}$ \\
\hline 1 & 9 & 13 & 2.4 & 0 \\
\hline
\end{tabular}

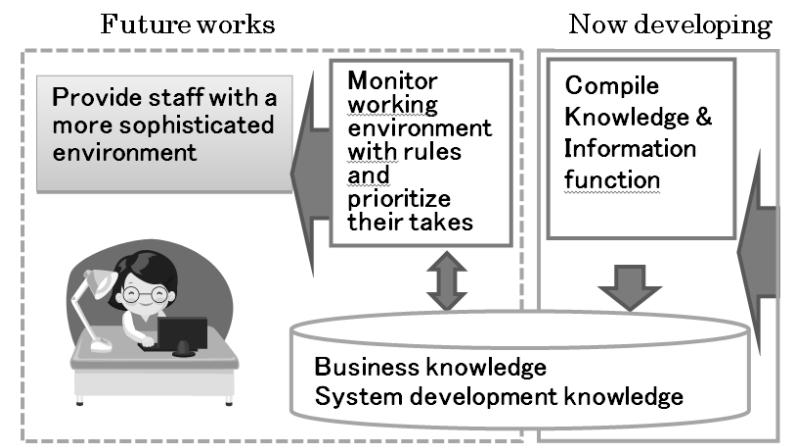

\section{Cause for} decreasing of productivity

Remanufacturing operation

Misunderstanding the requirements Assumption

Fig. 1. Decision support agent software

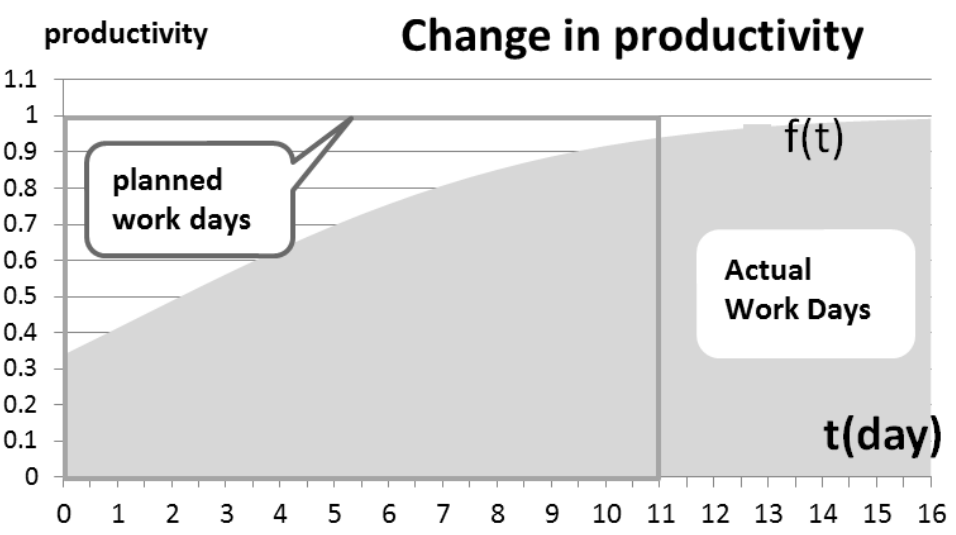

Fig. 2. Curve of productivity and actual work days 
The area of square in Figure 2 shows the planned work days and graph shows actual work days. Figure 2 shows the difference of actual work days and planned work days. In this example, it was estimated that it would take 11 days to finish the part of the project, however 25 days were required. The number of actual work days shown Figure 2 as the area under the curve $\mathrm{F}(\mathrm{t})$ were integrated using $\mathrm{F}(\mathrm{t})$ and $\mathrm{t}(\mathrm{time})$. The number of calculated actual work days was 12.8 days, while estimated work days were 11 days. In this example, therefore, calculated actual work days are nearly equal to planned work days. If high productivity achieved, then work will finish according to the schedule. Preparation work is necessary to achieve the expected level of productivity. The productivity does not increase if there are mistakes in preparation. Mistakes in preparation are caused by lack of knowledge or appropriate preparation work not be done. It is necessary for all subjects to decide what they must do before beginning work. Then, this paper proposes a method to recognize the work launch date. The work launch date is the day when information gathering and a preliminary examination of the project is begun. Assigning a work launch date which allows all subject to complete appropriate preparation work in anticipation of the planned work start date is necessary in order to achieve high earlier in the work cycle and shorten the number of work days. Because it is inevitable that there many tasks to be completed simultaneously, for example; scheduled task, preparation task for the next task, and troubleshooting work, it is important for subject to judge what they should do during preparation work phase as follows in Figure 3. All subject needs to prioritize their tasks. Then the psychological value which subject set on each task effects how they prioritize their takes. The psychological value which subject set on each task is limited by the short-term memory and their actual understanding at each task. Then, the decision support agent should support the selection of the most important task to do at each specific time. During any task it is especially necessary to make time to prepare for the next scheduled task. Then, the decision support agent should understand each subject's working characteristic, their skill and their involvement in other tasks. Prioritization mistakes during the preparation work phase causes schedule delays and cost overruns in projects. Work efficiency during the entire project decreases because of mistakes in preparation.

\section{Set the Work Priority Level}

Selecting the appropriate work that should be done at any given time is very important in order to increase the productivity of a project. The efficiency of the subsequent work does not increase when there are preparation mistakes in the project. It becomes impossible for the subject to accurately set a priority level for each task accurately when two or more tasks are being executed. Especially, because environmental conditions change hour by hour, it is difficult to select an appropriate task. Usually in such a case tasks are selected according to the experience of the subject. Then, one of the support functions of the decision support agent is to set appropriate priority levels for each task. Awareness of the environmental condition is 
necessary in order to select the work accurately. Then, the task selection process was examined by the questionnaire which has some completion targets; today and tomorrow, the day after tomorrow and complete in one week. For example, the task which should be done by today is review of the plan. The task which should be done by tomorrow is creating the schedule of tasks. The task which should be done by the day after tomorrow is creating documents of tasks. The task which should be done one week after is checking the report of tasks. Figure 4 shows the result of the subject selection process when subjects are asked to choose which tasks they would begin working on during three time periods; today, tomorrow, the day after tomorrow. In the questionnaire subjects are asked to order three out of four tasks over three days(designated today, tomorrow and the day after tomorrow); by according to their first, second and third priorities. The task which subjects wants to begin previously has high priority. Figure 5 shows the results in a situation similar to Figure 4 when subjects are asked to choose which tasks they would begin working on during four time periods; today, tomorrow, the day after tomorrow, one week after. From the above results, the priority level of the tasks is set according to the time limit in logical in Figure 4. However, the priority level of tasks is not set according to the time limit in Figure 5. Figure 5 show that subjects do not always consider the time limit when prioritizing tasks over a longer range of time. Subjects are expected to select tasks according to the time limit, and not their individual skills. In actual working situations the prioritization of tasks would be left to the subject's individual skills. A Person's short-term memory is one reason why appropriate work cannot be selected. The shortterm memory is maintained for only a few minutes. Because the time when subjects get the information about the tasks is different, prioritizing the tasks is not correctly evaluated in the subjects' minds. It is said that human can memorize only 10 pieces in a few seconds [11][12]. There is a limitation in the number of tasks which a subject can prioritize within a specific time.

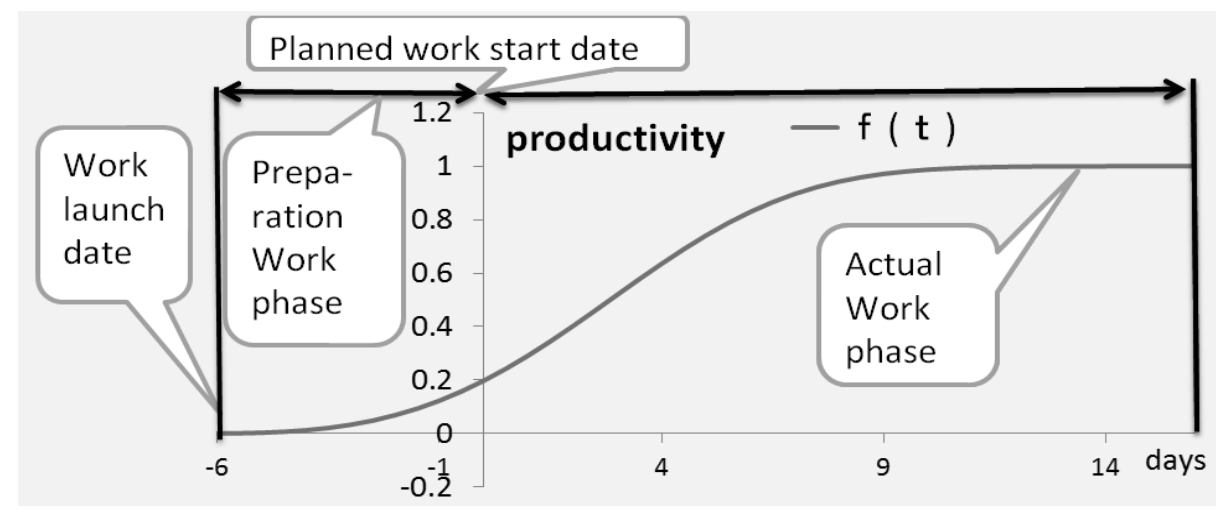

Fig. 3. work start date and work launch date 


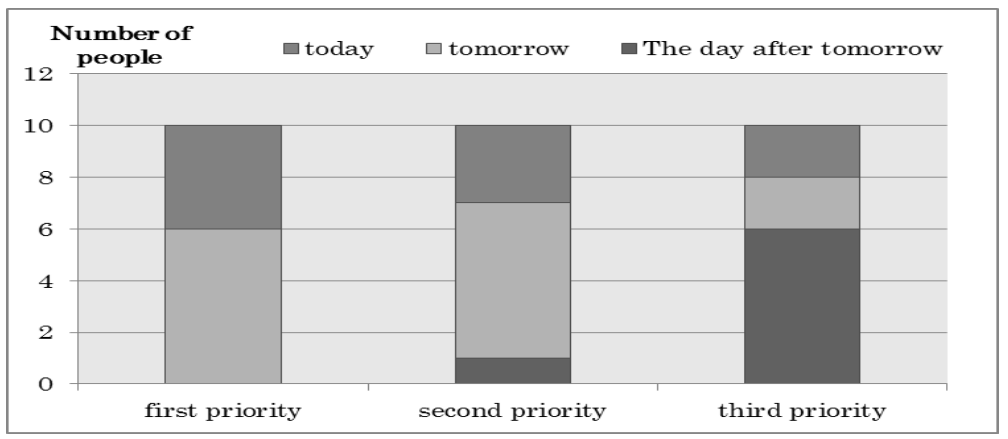

Fig. 4. Priority level of today, tomorrow, and the day after tomorrow's work

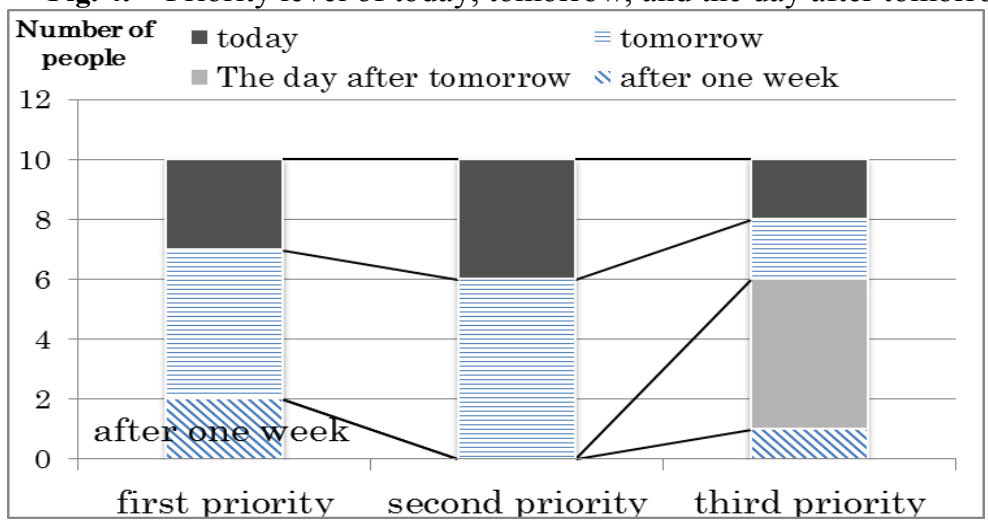

Fig. 5. Priority level of work after today, tomorrow, the day after tomorrow, and one week

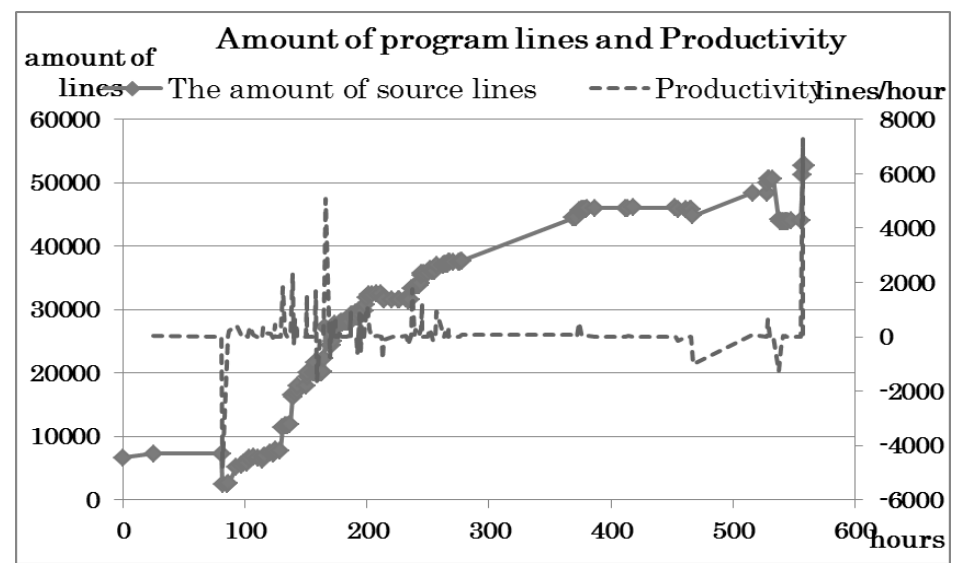

Fig. 6. Changes in productivity 
Table 2. Reasons why productivity decreases

\begin{tabular}{|r|l|}
\hline \multicolumn{1}{|l|}{ NO } & Reason why productivity decreases \\
\hline 1 & Insufficient time to revise work according to new specifications \\
\hline 2 & Revision work to correct cording errors \\
\hline 3 & Revisions in cording standards following review \\
\hline 4 & Revisions in order to improve execution efficiency \\
\hline
\end{tabular}

\section{Changes in Productivity}

There are changes in productivity in the system development project as follows in Figure 6.Figure 6 shows productivity during the system development project. Productivity is measured according to increases or decreases in the number of lines of source code per an hour. The programming criteria of productivity which we have is $60 \sim 200$ Line/day(Not include comments). The main reasons why productivity decreases are shown in table 2. From table 2, we can understand that it is necessary to clarify specifications and avoid violations of coding standards in order to improve productivity. Additionally, revisions in cording following review or specification changes are a one of the major causes of work delays. Offering appropriate knowledge is important to improve the productivity of staffs. Thus it is necessary to compile not only technical knowledge for programing but also knowledge for assessing of requirements of clients. One of functions to compile many kind of knowledge for decision support agent is creating. Additionally prioritizing tasks is vital to offering appropriate knowledge when it is needed. It is necessary to evaluate correctly the difficulty of their tasks according to their current working situation. Observation of the environmental conditions in real time is needed in order to evaluate the appropriate time when appropriate knowledge should be offered. It is necessary to be aware of the changes in the work situation to prioritize object's tasks. Productivity is changing every day. Prioritizing tasks appropriately is important to prevent cost overruns and delays in system development project.

\section{Decision support agent}

This paper aims to demonstrate the efficient of the decision support agent. This decision support agent should have the function to evaluate the value of knowledge and offer that knowledge to the subjects at the appropriate time. Additionally, the decision support agent should have the function to prioritize subjects' tasks in all stages of the project according to the environmental situation. Importantly, Figure 7 
shows that subjects give the same level of priority to tasks both one week and one month in the future, thus leading to incorrect prioritization of their assigned tasks. Because subjects cannot effectively prioritize tasks further than one week in the future (see Figure 7), it is necessary to support subject's prioritization of tasks. Additionally, the decision support agent is needed to support prioritization of subjects' tasks when dealing with various kinds of interruptions. The decision support agent should also have the function of taking into account the subjects' work pat-terns as follows in Figure 8 . Figure 8 shows a histogram of the self-reported level of concentrated for two subjects during a typical day of work on the system development project. Then, this paper proposes the decision support agent in Figure 1 . The decision support agent prioritizes their tasks according to the score obtained by the following Expression (2). Expression (2) shows the $f(x, t)$; function which calculates of prioritization of tasks according to their complexity. This $f(x, t)$ is the most important function of Decision support agent. Because as tasks become more complex, the figures become larger. In this function smaller values indicate a higher priority. Simple task is needed a few knowledge. It is important that tasks can be done in order of it is easy to work and simple. This $f(x, t)$ shows priority level of the task $\mathrm{x}$ at time t. $g(x, t)$ shows the number of knowledge for completing the task at a specific time t. $h\left(x, t_{1}\right)$ shows proportion to have obtained knowledge for completing the task at time t. Table 3 shows the expected effect when the priority level of tasks are appropriately set by this function; $\mathrm{f}(\mathrm{x}, \mathrm{t})$, and revision work is not generated. The productivity of the system development project is shown by the amount of increase in the amount of source code.

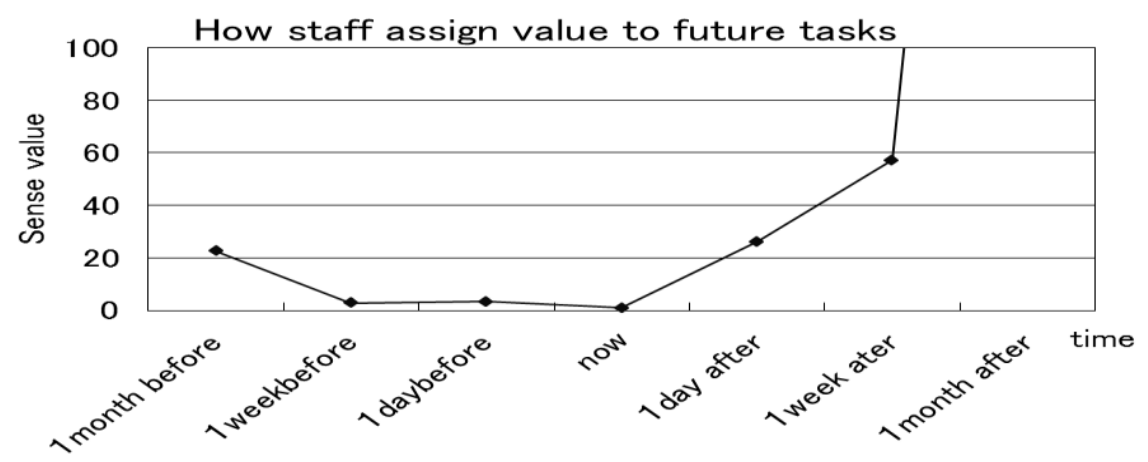

Fig. 7. Task priority values

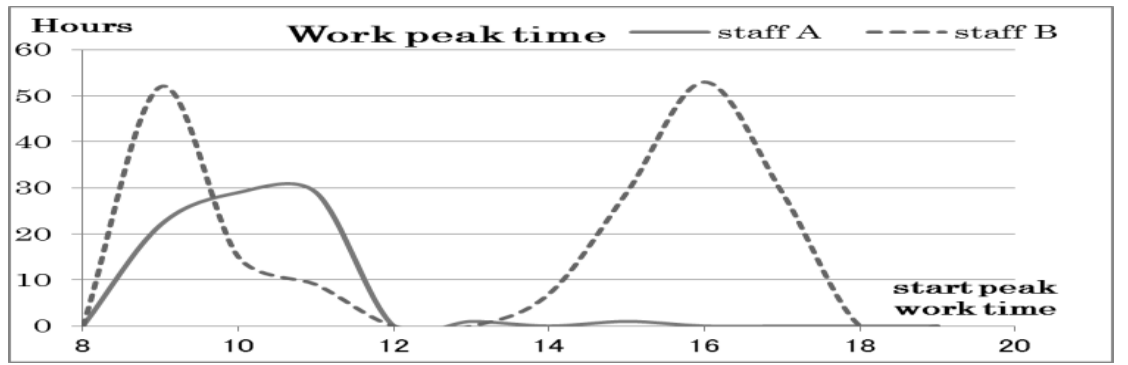

Fig. 8. Work patterns of subjects 


$$
f(x, t)=g(x, t) h(x, t)
$$

\section{Discussion}

In this study the researcher gathered data from an actual information retrieval software project. In order to increase the productivity of software development, this study proposes a formal or explicit work lunch date be set. The work launch date is the day when information gathering and a preliminary examination of the project is begun. In the management of a project launch date, a preparation work phase will be added before the actual work phrase. In the preparation work phase it is necessary to achieve a required level of productivity for the scheduled work. During this preparation work phase, there are many tasks which must be done at specific times. For example; scheduled tasks, preparation for the next stage, and troubleshooting. It is important for subjects to prioritize when must begin each specific task. It is also necessary to schedule their task in detail during each week. Then, this study proposes a decision support agent which is able to prioritize objects' tasks according to the score generated by the function in Expression (2) and which offers subjects applicable knowledge. Additionally, this agent should take into account the subjects' work patterns as shown in Figure 8. Although in the function in Expression (2) the connection between tasks is not expressed. Future tasks should take into account the environmental information to prioritize the tasks appropriately and clarify the effect of the prioritizing function; $\mathrm{f}(x, t)$.

Table 3. Expected effect

\begin{tabular}{|c|c|c|c|c|}
\hline project name & L(lines) & D(lines) & H 1 (hours) & H2(hours) \\
\hline A & 44478 & 1348 & 964 & 28.9 \\
\hline B & 52746 & 21505 & 1616 & 618 \\
\hline C & 8589 & 91 & 973 & 10.7 \\
\hline L : & The total number of lines written \\
D : & The number of deleted lines \\
H1: & Total working hours \\
H 2: & Working hours which could be saved if revision work is avoided.
\end{tabular}

Yokohama, Japan, $7^{\text {th }}-9^{\text {th }}$ July 2014 


\section{Conclusion}

Meeting budget, finishing on schedule, and maintaining high quality are all important in project management. Because project managers and engineers are usually working on multiple projects simultaneously, they must be able to make appropriately prioritized decisions in order to achieve these three goals. Then, this paper shows that it is effective to schedule a formal work launch date one week prior to the planned work start date, and to prioritize engineers' tasks appropriately. However, further research and study is needed to refine and improve the method of prioritizing engineers' tasks especially in the week before the planned work start date.

\section{Acknowledgment}

This work was supported by JSPS KAKENHI Grant Number 24500266.

\section{References}

[1]Parviz F. Rad,kou itou,translation, (2004) "PROJECT ESTIMATING COST MANAGEMENT",Seisannsei syuxtupan

[2]Project Management Inst (2009) "A Guide to the Project Management Body of Knowledge: Official Japanese Translation"

[3] Paul S. Royer,Nobuo Minemoto,translation, (2009)"Project Risk Management", Seisannsei syuxtupan

[4]Parviz F.rad, Itou Kou translation(2004)" PROJECT ESTIMATING AND COST MANAGEMENT,Seisannsei syuxtupan

[5]M. Jeffery Tyler(2011) "Practical Project Evm: The Application of Earned Value Management to Project Management", Springer

[6]Rafal Rzepka, Yali Ge, and Kenji Araki(2006) , "Common Sense from the Web? Naturalness of Everyday Knowledge Retrieved from WWW',Journal ref: Jour-nal of Advanced Computational Intelligence and Intelligent Informatics, Vol.10, No.6 pp. 868-875

[7]Rakesh Agrawal Ramakrishnan Srikant(1995), “ Mining Sequential Pat-terns ”,Proc 1995 int. Conf. on Data Engineering (ICDE95),pp.3-14

[8]Tetsuji Nakagawa , Yuji Matsumoto(2002), "Detecting Errors in Corpora Using SupportVector Machines," Proceedings of the 19th International Conference on Computational Linguistics(COLING 2002), Taipei, Taiwan, pp.709-715

[9]Mochida(2003) "Dynamic Knowledge Collection System Using,Web Technol-ogy”,Journal of Biomedical Fuzzy Systems Association, VOL.5 NO.1 Au-gust,BMFSA,pp 31-36

[10]Mochida(2011) "Knowledge Mining for Project Management and Execu-tion",Journal of Advanced Computational Intelligence and Intelligent Infor-matics,VOL.15 NO.4, Fuji Technology Press,pp 454-459

[11]P.H. Lindsay,D.A. Norman,Sachio nakamizo translation(1989),"Human Information Processing Japanese Translation 2 ", SAIENSU-SHA Co.,Ltd., pp. 52-53

[12]P.H. Lindsay,D.A. Norman,Sachio nakamizo translation(1989),"Human Information Processing Japanese Translation 3 ”, SAIENSU-SHA Co.,Ltd., pp. 111-113 